\title{
Ultrasonographic analysis of the anatomical relationship between femoral vessels in the upper part of thigh in critically ill patients - a cross sectional study
}

\author{
Suresh Kumar V.K. ${ }^{1}$, Vijayan D. ${ }^{2}$, Kunhu S. $^{3}$, Varghese B. ${ }^{4}$ \\ ${ }^{1}$ Dr. Suresh Kumar V.K., Senior Consultant, ${ }^{2}$ Dr. Deepak Vijayan, Senior Consultant, ${ }^{3}$ Dr. Shamim Kunhu, Associate \\ Consultant; above all authors are affiliated with Department of Critical Care Medicine, Kerala Institute of Medical \\ Sciences, Trivandrum, Kerala, ${ }^{4}$ Dr. Boban Varghese, Consultant ICU Physician, Valluvanadu Hospital, Ottappalam, \\ Kerala, India
}

Corresponding Author: Dr. Suresh Kumar, Senior Consultant, Department of Critical Care Medicine, Kerala Institute of Medical Sciences, Trivandrum, Kerala, India. E-mail: vk_sureshkumar@yahoo.co.in

\begin{abstract}
Objective: Femoral vessels are one of the frequently used sites of cannulation in intensive care units. In resource limited settings cannulations are done blindly without ultrasonographic guidance based on a traditional belief that in the upper thigh vein keeps a medial relationship to artery. In this trial we tried to analyse the anatomical relationship of femoral vein to femoral artery using ultrasound in critically ill patients. Methods: This cross sectional study analysed the anatomical relationship of femoral vein to femoral artery at $2 \mathrm{~cm}, 4 \mathrm{~cm}$ and $6 \mathrm{~cm}$ from the mid inguinal point in both thighs of the patients using ultrasonography. The study was done among patients admitted in a multidisciplinary intensive care unit. Results: Three hundred limbs of one hundred and fifty patients were analysed by ultrasonography. A total of 900 measurements were taken at three different levels of both legs. At $2 \mathrm{~cm}$ below the mid inguinal point, in 256 limbs $(85.3 \%)$ femoral vein was medial to femoral artery (95\% Confidence Interval $82.82 \%$ to $89.14 \%$ ), at $4 \mathrm{~cm}$ below the mid inguinal point, in $210 \mathrm{limbs}(70 \%)$ femoral vein was posteromedial to femoral artery (95\% CI64.47\% to $75.13 \%)$, and at6 $\mathrm{cm}$ below the mid inguinal point in 200 limbs (66.7\%) femoral vein was posterior to femoral artery (95\% CI 61.02\% to $71.98 \%$ ). Conclusion: Femoral vein showed variable relationship to femoral artery in the upper part of the thigh. As the distance increased from mid inguinal point, variation from normal relationship was also found to be increasing.
\end{abstract}

Key words: Ultrasound, Anatomical relationship, Femoral vessels, Upper thigh

\section{Introduction}

Femoral vessels are one of the frequently used sites of cannulation for various purposes in critical care settings [1]. Femoral vessels are contained in the femoral triangle in the upper part of the thigh. According to literature, femoral triangle (trigonum femorale; Scarpa's triangle) corresponds to the wedge shaped depression seen immediately below the fold of the groin [2]. The first $4 \mathrm{~cm}$. of the vessel is enclosed, together with the femoral vein, in a fibrous sheath, the femoral sheath. Femoral vein keeps a medial position to femoral artery until at the apex of the femoral triangle where it becomes posteromedial to artery [2]. The femoral site has numerous advantages both with elective vascular access and in critically ill patients.

Manuscript received: $26^{\text {th }}$ November 2018

Reviewed: $6^{\text {th }}$ December 2018

Author Corrected: $11^{\text {th }}$ December 2018

Accepted for Publication: $18^{\text {th }}$ December 2018
For critically ill patients, it is relatively free of other monitoring and airway access devices, allowing arm and neck movement without impeding the access line [1]. Femoral access avoids the risks of hemothorax and pneumothorax, which is particularly important in patients with severe coagulopathy or profound respiratory failure [1]. Similarly femoral artery is also used frequently for arterial blood pressure monitoring in critical care settings. In addition, the common femoral vein is often used for central venous access during emergency situations, because of its relative safe and accessible location with predictable anatomical landmarks. In addition, the femoral site permits cannulation attempts without interruption of cardiopulmonary resuscitation during cardiac arrest [1]. Most of the time vascular access procedures are done blindly, especially in resource limited countries, taking into 
Original Research Article

consideration the traditional description from anatomy literature that femoral vein will be medial to femoral artery in the upper part of the thigh. In a study regarding the utility of blind percutaneous jugular venous cannulation in resource limited settings it was shown that average number of passes to obtain the vascular access was 1.6 with $7.6 \%$ complication rate. A cross sectional done survey done among emergency physicians of United States regarding the usage of ultrasound guided central venous line placement has shown that the utility of ultrasonography was still poor and faces many barriers. A similar survey done among French intensivists showed that a proportion of intensivists are still utilising blind landmark technique rather than ultrasound guidance in placing central venous lines. In this trial we tried to define the anatomical relationship between the vein and artery at the upper part of thigh $[3,4,5]$.

\section{Materials and Methods}

Aim of this study was to describe the anatomical relationship of femoral vein to femoral artery at three different points from mid inguinal point viz $2 \mathrm{~cm}, 4 \mathrm{~cm}$ and $6 \mathrm{~cm}$.

Type of the study: This was a cross sectional study.

Place of the study: The study was done in patients admitted toa multidisciplinary intensive care unit of a tertiary level hospital.

Inclusion criteria: All patients getting admitted in a multidisciplinary intensive care unit having 18 years or above18 years of age. Exclusion criteria: Patients with hip trauma, previous history of femoral vascular surgery, previous history of pelvic trauma and patients having any vascular catheter in situ were excluded from the trial.

Sampling method \& sample collection: To document the position of femoral vein with respect to femoral artery ultrasonography was used by a trained person at three different levels in the upper part of thigh viz $2 \mathrm{~cm}, 4 \mathrm{~cm}$ and $6 \mathrm{~cm}$ below the mid inguinal point.

Statistical methods: Expecting that $65 \%$ of patients would have a variation from normal anatomy based on a study, it was calculated that 300 legs had to be analyzed to obtain this proportion with $95 \%$ confidence interval [6]. Data entry was done in Excel and analyzed using EpiInfo7. Continuous variables were expressed as mean and standard deviation and categorical variables were expressed as proportions with $95 \%$ confidence limits. Significance of difference in means assessed by student-t test / ANOVA for normally distributed variables or non-parametric tests for variables which were not normally distributed and significance of proportion between groups were tested by Chi-square test / fisher exact test, wherever applicable. Approval from Hospital Ethics Committee was obtained prior to initiating this study. Patients were put in the supine position. Mid inguinal point was identified using anatomical land marks and it was marked by a marker pen. The femoral vein was examined using linear probe of a portable ultrasound device. After applying ultrasound gel to the skin, a $25 \mathrm{~mm}$ broadband (8-12 Mega Hertz) linear transducer probe was applied perpendicular to the skin and axis of the leg, transversely across femoral vein at $2 \mathrm{~cm}, 4 \mathrm{~cm}$ and $6 \mathrm{~cm}$ below the mid inguinal point without compression (Figure 1).

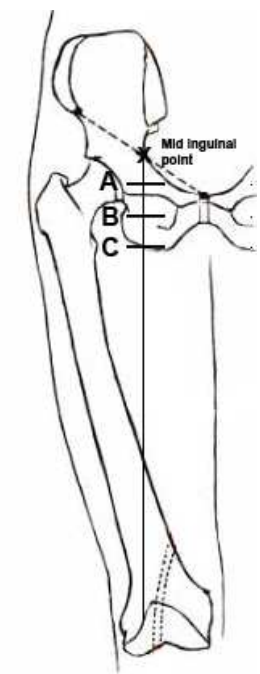

Figure-1: A - $2 \mathrm{~cm}$ below mid inguinal point, B - $4 \mathrm{~cm}$ below mid inguinal point, $\mathrm{C}-6 \mathrm{~cm}$ below mid inguinal point 


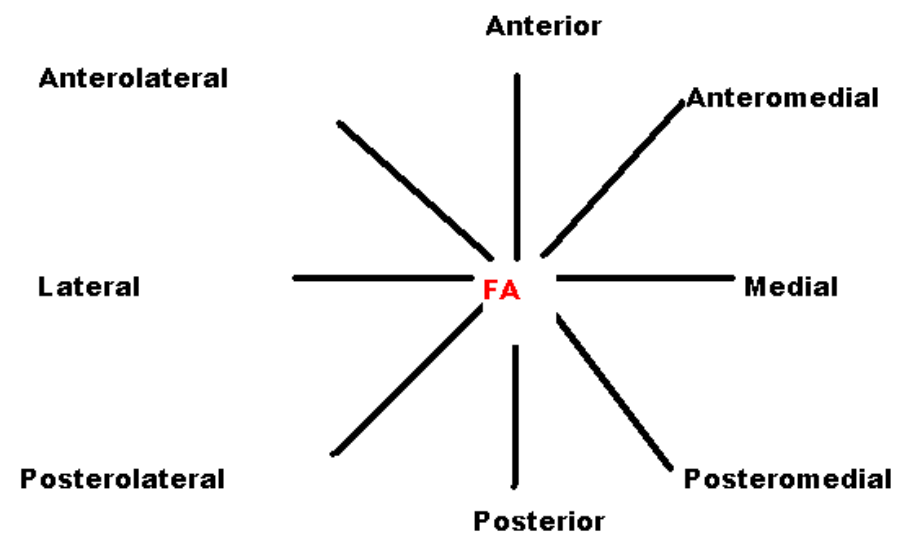

Figure-2

The vein was identified by the absence of pulsation, demonstration of collapsibility under gentle pressure, the direction of blood flow on the doppler colour flow map, phasic variation with respiration and augmentation. Femoral artery was identified by pulsatility and spectral doppler. The location of the vein was defined in relation to artery as anterior, posterior, medial, lateral, anteromedial, anterolateral, posteromedial and posterolateral as per the below shown figure (Figure 2).

\section{Results}

Three hundred limbs of one hundred and fifty patients were analysed by ultrasonography. 105 patients were males (70\%) and 45 patients $(30 \%)$ were females. Mean age of the patients was 57.29 years (standard deviation 17.12 years). Mean height of the patients was $167.18 \mathrm{~cm}$ (standard deviation $8.45 \mathrm{~cm}$ ). A total of 900 measurements were taken at three different levels of both legs.

When analyzed the vascular anatomical relationship at $2 \mathrm{~cm}$ below the mid inguinal point, in 256 limbs (85.3\%) femoral vein was medial to femoral artery (95\% CI: 82.82\%, 89.14\%). In 36 limbs (12\%) femoral vein was posteromedial to artery with varying degrees of overlap between the two. In 4 limbs $(1.3 \%)$ femoral vein was posterior to femoral artery. In another 4 limbs $(1.3 \%)$ femoral vein was anteromedial to femoral artery (Table 1$)$.

Table-1: Anatomical relationship of femoral vessels at $2 \mathrm{~cm}$ from mid inguinal point

\begin{tabular}{|c|c|c|c|}
\hline Relationship & Frequency & Percent & 95\% Conf Limits \\
\hline Anteromedial & 4 & 1.33 & $0.36 \%-0.38 \%$ \\
\hline Medial & 256 & 85.33 & $80.82 \%-89.14 \%$ \\
\hline Posteromedial & 36 & 12 & $8.5 \%-16.2 \%$ \\
\hline Posterior & 4 & 1.33 & $0.36 \%-3.38 \%$ \\
\hline
\end{tabular}

At $4 \mathrm{~cm}$ below the mid inguinal point, in 210 limbs (70\%) femoral vein was postero medial to femoral artery (95\% CI: $64.47 \%, 75.13 \%)$. In 59 limbs (19.7\%) femoral vein was medial to femoral artery and in 29 limbs $(9.7 \%)$ femoral vein was posterior to femoral artery (Table 2)

Table-2: Anatomical relationship of femoral vessels at $4 \mathrm{~cm}$ from mid inguinal point

\begin{tabular}{|c|c|c|c|}
\hline Relationship & Frequency & Percent & 95\% Confidence interval \\
\hline Medial & 59 & $19.67 \%$ & $15.32 \%-24.62 \%$ \\
\hline Posteromedial & 210 & $70 \%$ & $64.47 \%-75.13 \%$ \\
\hline Posterior & 29 & $9.67 \%$ & $6.57 \%-13.59 \%$ \\
\hline Posterolateral & 2 & $0.67 \%$ & $0.08 \%-2.39 \%$ \\
\hline
\end{tabular}

At $6 \mathrm{~cm}$ below the inguinal ligament in 200 limbs $(66.7 \%)$ femoral vein was posterior to femoral artery (95\% CI: $61.02 \%, 71.98 \%)$, in 89 limbs it was poster medial to femoral artery and in 7 limbs $(2.3 \%)$ it was posterolateral and in 4 limbs $(1.3 \%)$ femoral vein was medial to artery (Table 3$)$. 
Original Research Article

Table-3: Anatomical relationship of femoral vessels at $6 \mathrm{~cm}$ from mid inguinal point

\begin{tabular}{|c|c|c|c|}
\hline Relationship & Frequency & Percent & 95\% Confidence interval \\
\hline Medial & 4 & 1.33 & $0.36 \%-3.38$ \\
\hline Postero medial & 89 & 29.67 & $24.55 \%-35.19 \%$ \\
\hline Posterior & 200 & 66.67 & $61.02 \%-71.98 \%$ \\
\hline Postero lateral & 7 & 2.33 & $0.94 \%-4.75 \%$ \\
\hline
\end{tabular}

Table-4: Association of age, sex and height with abnormal anatomical relationship

\begin{tabular}{|c|c|c|c|c|c|c|}
\hline Variable & Abnormal & P value & Abnormal & P value & Abnormal & P value \\
\hline & at $2 \mathrm{~cm}$ & & at $4 \mathrm{~cm}$ & & at $4 \mathrm{~cm}$ & \\
\hline \multicolumn{7}{|l|}{ Sex } \\
\hline Male & $11(12 \%)$ & 0.43 & $65(72 \%)$ & 0.02 & $89(99 \%)$ & 0.8 \\
\hline Female & $3(15.7 \%)$ & & $176(84 \%)$ & & 207(99\%) & \\
\hline \multicolumn{7}{|l|}{ Height } \\
\hline$<170 \mathrm{~cm}$ & $28(13.8 \%)$ & 0.5 & $168(80 \%)$ & 0.5 & $207(98.5 \%)$ & 0.8 \\
\hline$>/=170 \mathrm{~cm}$ & $15(16.6 \%)$ & & $73(81 \%)$ & & $89(98.9 \%)$ & \\
\hline \multicolumn{7}{|l|}{ Age } \\
\hline$<60$ & $19(11.9 \%)$ & 0.14 & $132(82.5 \%)$ & 0.3 & $158(98.7 \%)$ & 0.8 \\
\hline$>/=60$ & $25(17.9 \%)$ & & $109(77.9 \%)$ & & $138(98.5 \%)$ & \\
\hline
\end{tabular}

When sex, age and height were compared for any significance for the variation, they were found to be not significant (Table 4).

\section{Discussion}

Vascular access is an important and most frequently performed invasive procedure in intensive care units. This is used for various purposes including central venous access, arterial pressure monitoring, intra arterial balloon pump (IABP) and Extra Corporeal Membrane Oxygenation (ECMO) cannulation. This procedure has got inherent complications including vascular injury, perivascular hematoma and arteriovenous fistula [1].

This risk increases especially when these procedures are done blindly without any ultrasonographic guidance. Traditional anatomical literature describes the relationship of femoral vein to femoral artery as vein is medial to artery throughout its course in the femoral triangle except in its apex where the vein is becoming postero medial to artery. The apex of femoral triangle is around $10 \mathrm{~cm}$ from inguinal ligament as per the standard anatomical literature [6].

Baum et al in 1989 assessed variations in the relationship between common femoral artery (CFA) and common femoral vein ((CFV) using CT scan of pelvis. They noticed that in $65 \%$ cases the CFA overlapped $\mathrm{CFV}$ in antero posterior plane, among which more than $25 \%$ overlap, was noticed in $8 \%$ of cases [7]. In a study done byE. P. Souza Neto et al in one hundred and forty two children using ultrasonography, $9.8 \%$ of anatomical variations were found for femoral vein. In this study the major noted anatomical variation was that femoral vein was antero medial to femoral artery [8]. In another study by $\mathrm{P}$. Hughes et al in 50 consecutive patients admitted in intensive care unit by ultrasonography at the level of inguinal ligament, $28 \%$ of patients showed varying overlap in right side and in $41 \%$ of patients there were varying overlap in left side. As comes down from inguinal ligament to $4 \mathrm{~cm}$ below it in $100 \%$ of patients there was varying overlap in right side and in $96 \%$ of patients showed varying overlap in left side[9].

Accidental femoral arterial puncture is a recognised complication of femoral venous access. This complication may happen upto $10 \%$ of patients undergoing femoral venous access [10,11]. This can be complicated with periarterial hematoma [12], pseudo aneurysm, arteriovenous fistula [13,14], thrombosis and haemorrhage [15]. Complications related to femoral arterial puncture for any therapeutic procedure varies between $0.11 \%$ to $0.47 \%$ [16]. Similarly the site of puncture also has got a role in deciding complications. Puncture below the femoral bifurcation is associated with higher incidence of pseudo aneurysm and above the inguinal ligament is associated with retroperitoneal haemorrhage [17-18]. In this trial at $2 \mathrm{~cm}$ below mid inguinal point, out of 300 limbs analysed in 36 limbs $(12 \%)$ vein showed posteromedial relation with varying 


\section{Original Research Article}

degrees of overlap and in 4 limbs $(1.3 \%)$ vein was posterior to artery. This finding has implications in vascular access. In limbs showing posteromedial and exact posterior relationship between artery and vein, likelihood of arterial puncture and subsequent complications may be high when such procedures are done without anultrasonographic guidance for femoral venous access. In $4 \mathrm{~cm}$ below the mid inguinal point, in 210 limbs $(70 \%)$ vein was posteromedial to artery with varying degrees of overlap.

This also imparts significant risk to arterial puncture when attempting venous access blindly without ultrasonographic guidance. In 59 limbs (19.7\%) only, vein was exactly medial to artery.

This finding is contrary to traditional information in anatomy literature where it states that vein is medial to artery in femoral sheath in femoral triangle. Extent of femoral sheath is around 2 to $4 \mathrm{~cm}$ from inguinal ligament [2]. $6 \mathrm{~cm}$ below the mid inguinal point, in 200 $(66.7 \%)$ limbs vein was exactly posterior to artery imparting high chance for arterial puncture and subsequent complications if venous access being tried without ultrasound guidance.

This anatomical relationship also contrary to traditional anatomical literature which states that at apex of femoral triangle only, which is around $10 \mathrm{~cm}$ from inguinal ligament, femoral the vein becomes posteromedial to femoral artery.

The anteroposterior and posterior relationship of the vein to artery also has got implication especially when trying for arterial cannulation for various procedures like arterial line placement, IABP placement and ECMOcannulation. In this situation the chance of developing artereo venous fistula may be high.

Incidence of this relationship was $1.3 \%, 9.7 \%$ and $66.7 \%$ at $2 \mathrm{~cm}, 4 \mathrm{~cm}$ and $6 \mathrm{~cm}$ respectively from the mid inguinal point. This observation was also contrary to the traditional anatomy literature. Major drawback of this cross sectional study was that we did not measure the relationship of vasculature at different leg positions which may have an influence as per the results from previous studies. Secondly the degree of overlap between the femoral vessels was not quantified in this trial.

\section{Conclusion}

Contrary to the traditional concept about the anatomical relationship between femoral vessels in upper thigh, this study showed significant variation. The variation from expected at $2 \mathrm{~cm}$ below the mid inguinal point was $14.7 \%$, at $4 \mathrm{~cm}$ from mid inguinal point was $80.3 \%$ and at $6 \mathrm{~cm}$ from mid inguinal point was $98.7 \%$

Recommendation: Hence we recommend that when femoral vascular access is attempted blindly, puncture site within $2 \mathrm{~cm}$ from the mid inguinal point may reduce complications or ultrasound guidance may be used to direct the access.

Acknowledgement: We would like to thank Dr. Sanjeev Nair, Associate Professor, Department of Pulmonary Medicine, Medical College, Trivandrum for his valuable opinion and advice.

\section{Authors' contributions}

1. Conception and design of the study.

2. Supervision, data collection and processing

3. Analysis and interpretation of the data

4. Literature review and writing the manuscript

\section{Funding: Nil, Conflict of interest: None Permission of IRB: Yes}

\section{References}

1. Troianos CA, Hartman GS, Glas KE, et al. Guidelines for performing ultrasound guided vascular cannulation: recommendations of the American Society of Echocardiography and the Society of Cardiovascular Anesthesiologists. J Am SocEchocardiogr. 2011 Dec; 24(12):1291-318. doi: 10.1016/j.echo.2011.09.021.

2. Chaurasya B D. Human anatomy; regional and applied dissection and clinical. New Delhi: CBS publicshers \& Distributors; 2010.

3. Komolafe O, Olatise O. Utility of blind percutaneous jugular venous cannulation in resource-limited settings. J Vasc Access. 2017 Jan 18; 18(1):26-29. doi: 10.5301/ jva.5000627. Epub 2016 Nov 14.

4. Buchanan MS, Backlund B, Liao MM, et al. Use of ultrasound guidance for central venous catheter placement: survey from the American Board of Emergency Medicine Longitudinal Study of Emergency Physicians. AcadEmerg Med. 2014 Apr;21(4):416-21. doi: 10.1111/acem.12350.

5. Maizel J, Bastide MA, Richecoeur J, et al. Practice of ultrasound-guided central venous catheter technique by the French intensivists: a survey from the BoReal study group. Ann Intensive Care. 2016 Dec;6(1):76. doi: 10.1186/s13613-016-0177-x. Epub 2016 Aug 8. 


\section{Original Research Article}

6. Grant J, Basmajian J. Grant's Method of Anatomy. Baltimore: Williams \& Wilkins; 1980.

7. Baum PA, Matsumoto AH, Teitelbaum GP, Zuurbier RA, Barth KH. Anatomic relationship between the common femoral artery and vein: CT evaluation and clinical significance. Radiology. 1989;173(3):775-77.

8. P Souza Neto E, Grousson S, Duflo F, et al. Ultrasonographic anatomic variations of the major veins in paediatric patients. $\mathrm{Br} \mathrm{J}$ Anaesth. 2014 May; 112(5):879-84. doi: 10.1093/bja/aet482. Epub 2014 Feb 10.

9. Hughes P, Scott C, Bodenham A. Ultrasonography of the femoral vessels in the groin: implications for vascular access. Anaesthesia. 2000 Dec; 55(12):1198202.

10. Getzen LC, Pollak EW. Short-term femoral vein catheterization.A safe alternative venous access? Am J Surg. 1979 Dec; 138(6):875-8.

11. Williams JF, Seneff MG, Friedman BC, McGrath, Brian j, Gregg, Richard, Sunner, Jennie RN; Zimmerman, Jack E. Use of femoral venous catheters in critically ill adults: prospective study. Critical Care Medicine 1991April; 19(4): 550-53.
12. Gilston A. Letter: Cannulation of the femoral vessels. Br J Anaesth. 1976 May; 48(5):500-1.

13. Fuller TJ, Mahoney JJ, Juncos LI, et al. Arteriovenous fistula after femoral vein catheterization. JAMA. 1976 Dec 27; 236(26):2943-4.

14. Grassi CJ, Bettmann MA, Rogoff P, Reagan K , Harrington DP. Femoral arteriovenous fistula after placement of a Kimray $\square$ Greenfield filter. American Journal of Roentgenology. 1988 Nov; 151(4): 681-2.

15. Hessel SJ, Adams DF, Abrams HL.Complications of angiography.Radiology. 1981 Feb;138(2):273-81.

16. Grier D, Hartnell G. Percutaneous femoral artery puncture: practice and anatomy. British Journal of Radiology. 1990; 63(752): 602-4.

17. Rapoport S, Sniderman KW, Morse SS, et al. Pseudoaneurysm: a complication of faulty technique in femoral arterial puncture. Radiology. 1985 Feb; 154(2):529-30. DOI:10.1148/radiology.154.2.3966139.

18. Altin RS, Flicker S, Naidech HJ. Pseudoaneurysm and arteriovenous fistula after femoral artery catheterization: association with low femoral punctures. AJR Am J Roentgenol. 1989 Mar; 152(3):629-31. DOI:10.2214/ajr.152.3.629.

\section{How to cite this article?}

Suresh Kumar V.K., Vijayan D., Kunhu S.,Varghese B. Ultrasonographic analysis of the anatomical relationship between femoral vessels in the upper part of thigh in critically ill patients - a cross sectional study. Int J Med Res Rev 2018; 6(08): 471-476. doi:10.17511/ijmrr.2018.i08.12. 